\title{
Association between markers of glycemia and carotid intima-media thickness: the MARK study
}

\author{
Manuel A. Gomez-Marcos ${ }^{1,2,3^{*}}$, Leticia Gomez-Sanchez ${ }^{1}$, Maria C. Patino-Alonso ${ }^{1,4}$, Jose I. Recio-Rodriguez ${ }^{1,2}$, \\ Natividad Garcia Regalado ${ }^{5}$, Rafel Ramos ${ }^{6,7,8,9}$, Ruth Marti ${ }^{6,7,9}$, Cristina Agudo-Conde ${ }^{1,2}$, \\ Emiliano Rodriguez-Sanchez ${ }^{1,2,3}$, Jose A. Maderuelo-Fernandez ${ }^{1,2}$, Luis Garcia-Ortiz ${ }^{1,2,3}$ and for the MARK Group ${ }^{5,10}$
}

\begin{abstract}
Background: Carotid intima-media thickness (C-IMT) is a reliable predictor of cardiovascular events. We Investigated the relationship between markers of glycemia and C-IMT in intermediate-risk cardiovascular patients.

Methods: This study analyzed 427 subjects, aged 35 to 74 years (mean, $60.3 \pm 8.5$ years), $55 \%$ women, enrolled into the MARK study. Including 231 subjects defined as normal glucose, 104 subjects classified as prediabetes and 92 with type 2 diabetes mellitus. Carotid ultrasound was used to measure C-IMT and the presence of plaques. Fasting plasma glucose (mg/dl) and glycated hemoglobin (\%) ( $\mathrm{HbA} 1 \mathrm{c}$ ) were measured using standard enzymatic automated methods. Postprandial glucose $(\mathrm{mg} / \mathrm{dl}$ ) was self-measured by patients at home $2 \mathrm{~h}$ after meals (breakfast, lunch and dinner) for 1 day.

Results: The C-IMT shows a positive correlation with fasting plasma glucose, postprandial glucose and HbA1c. Multiple linear regression analysis showed a positive association between HbA1C and C-IMT, with a $0.016 \mathrm{~mm}$ and $0.019 \mathrm{~mm}$ increase in mean and maximum C-IMT per $1 \%$ increase in HbA1c. In addition, an association between fasting plasma glucose and C-IMT was found with an increase of 0.004 and $0.005 \mathrm{~mm}$ in mean and maximum C-IMT per $10 \mathrm{mg} / \mathrm{dl}$ in fasting plasma glucose. We also observed a graded association between fasting plasma glucose, postprandial glucose and HbA1c and the presence of carotid target organ damage (TOD), with an odds ratio of $1.013,1.010$ and 1.425 , respectively.
\end{abstract}

Conclusion: The results of this study suggest that the fasting plasma glucose and $\mathrm{HbA1c}$, but not postprandial glucose, are associated with C-IMT media and maximum. The patients who present with a metabolic glucose alteration have more risk of developing carotid TOD.

Trial registration: ClinicalTrials.gov; Identifier: NCT01428934.

Keywords: Intima-media thickness, Fasting plasma glucose, Postprandial glucose, Glycosylated hemoglobin

\section{Background}

A positive relationship between the glycosylated hemoglobin (HbA1C), fasting plasma glucose and postprandial glucose with cardiovascular morbidity in diabetes patients has been shown in several studies $[1,2]$. In people free of diabetes, this association is not clear, and studies suggest that there is

\footnotetext{
*Correspondence: magomez@usal.es

${ }^{1}$ Primary Care Research Unit, the Alamedilla Health Center, 37003 Salamanca, Spain

${ }^{2}$ Castilla and León Health Service-SACYL, REDIAPP. IBSAL, Salamanca, Spain Full list of author information is available at the end of the article
}

a higher association with HbA1c [1, 3-6] than with others parameters. However, patients with type 2 diabetes and those with glucose intolerance present with a carotid thickness that is 0.13 and $0.04 \mathrm{~mm}$ wider than the carotid thickness of the control subjects. These results are similar in different ethnicities and in both sexes [7].

The association between HbA1c, fasting glucose and postprandial glycemia with the carotid intima-media thickness (C-IMT) is different in diabetic patients compared with non-diabetic people [8]. Studies that have analyzed the relationship between HbA1c and intima-media 
thickness of common carotid artery in non-diabetics are inconclusive. Studies showed a positive association between $\mathrm{HbA1c}$ and 1-h post load plasma glucose and CIMT [2, 3]. However, the Dong-gu study [4] showed that HbA1c level was independently associated with arterial stiffness, but not with carotid atherosclerotic parameters, in the overall population without diabetes. Choi et al. [9] recently showed an association with the presence of cholesterol fatty plaques in the coronary artery walls but not with the C-IMT in Korean diabetic patients. However, there was a positive association in Japanese diabetics with fatty plaques of cholesterol on the coronary artery walls [10].

A positive association between glycemia and C-IMT in the general population has been described in several studies [11, 12]. The association between postprandial glucose and the C-IMT that was analyzed by Kato et al. [13], using the 2-h plasma glucose measurement during an oral glucose tolerance test, was positively and independently associated with C-IMT in Japanese subjects with normal glucose tolerance, which is in agreement with the results published by Andreozzi F et al. [8]. Xing F et al. [6] found a relationship between the HbA1c and the basal glucose level C-IMT in prediabetic patients, but this association did not remain after an adjustment for other cardiovascular risk factors. Tanaka et al. [14] showed that the increase in glycemia one hour after $75 \mathrm{~g}$ of glucose overload was the only parameter that was associated with C-IMT, but Hot et al. [15] did not show that association.

Thus, the association of normoglycemic levels with subclinical cardiovascular measures remains controversial and is of particular interest, given that this association would potentially affect a larger proportion of the population.

The association between markers of glycemia and vascular structure in patients with intermediate cardiovascular risk has not been determined. In patients with intermediate cardiovascular risk, it is important to analyze new cardiovascular risk factors and the association between them for personalized risk stratification. Therefore, we investigated the relationship between markers of glycemia and vascular structure based on C-IMT in intermediate-risk cardiovascular patients.

\section{Methods}

\section{Study design}

This study enrolled 427 subjects, who were included at the baseline of the MARK study and who underwent fasting glucose, postprandial glucose and glycosylated hemoglobin (HbA1c) tests, and also carotid ultrasonography. The MARK study is a cross-sectional study to evaluate if ankle-brachial index (ABI) measures of arterial stiffness cardio-ankle vascular index (CAVI), postprandial glucose, glycosylated hemoglobin, self-measured blood pressure and presence of comorbidity are independently associated with the incidence of vascular events, and whether they can improve the predictive capacity of the current risk equations in the intermediate-risk population. The second step will be a 5-10-year follow-up to evaluate cardiovascular morbidity and mortality (NCT01428934) [16].

\section{Study population}

Population aged between 35 and 74 years who have an intermediate cardiovascular risk, defined as coronary risk between 5 and $15 \%$ at 10 years according to the Framingham adapted risk equation [17], vascular mortality risk between 1 and $5 \%$ at 10 years according to the SCORE equation [18] or moderate risk according to the 2013 European Society of Hypertension guidelines for the management of arterial hypertension [19]. This study analyzed 427 subjects enrolled in MARK study. Including 231 subjects defined as normal glucose, 104 subjects classified as prediabetes and 92 with type 2 diabetes mellitus. In the 335 patients without prior diagnosis of diabetes we have adapted the cut-offs of HbAlc, fasting plasma glucose (FPG) and postprandial glucose (PG) according to current American Diabetes Association criteria [20]. We have considered prediabetes if HbA1c between 5.7 and 6.4 or FPG between 100 and $125 \mathrm{mg} / \mathrm{dL}$ or PG between 140 and $199 \mathrm{mg} / \mathrm{dL}$ and not diagnostic de type 2 diabetes mellitus, and metabolism of glucose normal if HbA1c $\leq 5.7$ or FPG $\leq 100 \mathrm{mg} / \mathrm{dL}$ or PG $\leq 140$ and not diagnostic of type 2 diabetes mellitus or prediabetes.

The exclusion criteria were terminal illness, institutionalization at the appointment time or a personal history of atherosclerotic disease. Sample selection was done using a random sample from the population aged 35 to 74 years (both included) who had an intermediate cardiovascular risk. Recruitment and data collection for the study occurred from July 2011 to June 2013. A sample-size calculation indicated that the 427 patients included in this study constituted a sufficient sample for detecting a correlation coefficient of 0.135 between fasting glucose and C-IMT in a two sided test, with a level of significance of $95 \%$ (alfa risk 0.05 ) and a power of $80 \%$ (beta risk 0.20). The study was approved by an independent ethics committee in the Salamanca health area (Spain), and all participants gave written informed consent, according to the general recommendations of the Declaration of Helsinki [21].

\section{Measurements}

A detailed description has been published elsewhere regarding collection of clinical data, anthropometric measurements and analytical parameters [16].

\section{Laboratory determinations}

Venous blood sampling was performed between 08:00 and 09:00 after the individuals had fasted and abstained 
from smoking and the consumption of alcohol and caffeinated beverages for the previous $12 \mathrm{~h}$. Fasting plasma glucose, HbA1c, serum total cholesterol and highdensity lipoprotein (HDL) cholesterol concentrations were measured using standard enzymatic automated methods. Blood samples were collected in the Alamedilla Health Center and analyzed at the Salamanca Hospital, which was approved by the Spanish Society of Clinical Chemistry and Molecular Pathology external quality assurance programs. Postprandial glucose $(\mathrm{mg} / \mathrm{dl})$ was self-measured by patients at home $2 \mathrm{~h}$ after meals (breakfast, lunch and dinner) for 1 day using an Accuchek $^{\bullet}$ glucometer (Roche Diagnostics Corporation, Spain). Postprandial glucose was calculated as the average of the three measurements. We considered glucose metabolism to be impaired if the patient had diabetes or impaired fasting glucose (between 100 and $126 \mathrm{mg} / \mathrm{dl}$ ) or HbA1c (between 5.7 and 6.4) or postprandial glucose (between 140 and $200 \mathrm{mg} / \mathrm{dl}$ ) [14].

\section{Office blood pressure}

Office blood pressure (BP) was calculated as the average of the last two of three measurements of systolic blood pressure (SBP) and diastolic blood pressure (DBP) made using a validated sphygmomanometer (OMRON Model M10-IT). Measurements were made using the participant's dominant arm when they were in a seated position after at least $5 \mathrm{~min}$ of rest, with a cuff of appropriate size as determined by measurement of the upper-arm circumference according to the European Society of Hypertension recommendations [22].

\section{Assessment of vascular structure using carotid intima media thickness}

Two trained investigators performed the carotid ultrasound to assess carotid C-IMT before starting the study. Before the study, the reliability of the recordings was evaluated using the intra-class correlation coefficient, which showed values of 0.97 (95\% CI: 0.94 to 0.99 ) for intra-observer agreement of repeated measurements in 20 subjects, and 0.90 (95\% CI: 0.74 to 0.96 ) for interobserver agreement. According to the Bland-Altman analysis, the mean difference for inter-observer agreement (95\% limit of agreement) was 0.01 (-0.03 to 0.06). A Sonosite Micromax ultrasound (SonoSite, EE.UU device paired with a $5-10 \mathrm{MHz}$ multi-frequency highresolution linear transducer with Sonocal software was used for to automatically measure the C-IMT. There were 120 values obtained automatically, ten measurements in each of the 12 projections, to optimize reproducibility. The common carotid was measured after examining a 10-mm longitudinal section at a distance of $1 \mathrm{~cm}$ from the bifurcation, and measurements were also taken of the proximal wall. The lateral $\left(90^{\circ}\right)$, anterior $\left(45^{\circ}\right)$ and posterior $\left(135^{\circ}\right)$ projections in the distal wall followed an axis perpendicular to the artery to distinguish between two lines: one for the intima-blood interface and the other for the media-adventitious interface. A total of six measurements of the right carotid artery and six measurements of the left carotid artery were obtained, and the average values (average mean C-IMT and average maximum C-IMT) were automatically calculated by the software [23]. The measurements were obtained with the subject lying down, with their head extended and slightly turned opposite to the carotid artery that was examined. It was considered as carotid TOD if exists a plaque or a carotid IMT $>0.9 \mathrm{~mm}$. Presence of a plaque was identified by an IMT $\geq 1.5 \mathrm{~mm}$ or by a focal increase in thickness of $0.5 \mathrm{~mm}$ or $50 \%$ of the surrounding carotid IMT value [19].

\section{Others measurements}

Anthropometric measurements Body mass index (BMI) was calculated as weight $(\mathrm{kg})$ divided by height squared $\left(\mathrm{m}^{2}\right)$. A value of $>30 \mathrm{~kg} / \mathrm{m}^{2}$ was considered to define obesity.

\section{Lifestyles Tobacco}

Smoking history was assessed by asking questions about the participant's smoking status (smoker/non-smoker) and the number of cigarettes/day for the smokers. We considered smokers to include those who currently smoke or who have stopped smoking within the past year.

\section{Alcohol}

Alcohol consumption was assessed through a structured questionnaire and was expressed in grams per week.

Physical activity

Leisure time physical activity (LTPA) practice was collected using the Minnesota LTPA Questionnaire that was validated for Spanish men and women $[24,25]$. The questionnaire was administered by trained interviewers and it collected detailed information about physical activity during the preceding year, the number of times this activity was performed and the average duration of each activity on each occasion. Each physical activity has an intensity code, based on the ratio between the metabolic rate during PA practice and the basal metabolic rate. Consumption in mean metabolic equivalents (METs) -min was estimated over 14 days by multiplying the MET in physical activity with the duration (in minutes) and cumulative frequency in the month before the interview.

The individuals performing the different tests were blinded to the patient's clinical data. All assessments were made within a period of 10 days.

\section{Statistical analysis}

Continuous variables were expressed as the mean \pm standard deviation for normally-distributed continuous data, the 
median (interquartile range, IQR) for asymmetricallydistributed continuous data and as a frequency distribution for categorical data. Statistical normality was tested using the Kolmogorov-Smirnov test. Pearson correlation was performed to analyze the relationship between quantitative variables and Spearman's correlation was used to analyze the relationship between asymmetrically-distributed continuous data. Analysis of variance (ANOVA) was used to determine differences in the means between more than two categories of quantitative variables for symmetrically distributed continuous data. Comparisons between three or more groups were also made using ANOVA and differences between groups were assessed using the Bonferroni post hoc test.

We performed multiple linear regression analyses, one for each dependent variable, with C-IMT mean and maximum $(\times 100)$ to facilitate interpretation of fasting glucose, average postprandial glycemia and HbA1c as independent variables. We adjusted by age and gender (Model 1), and by age, gender, heart rate, smoker, body mass index, no HDL-cholesterol, systolic blood pressure, diabetes mellitus, antihypertensive drugs, lipid lowering

Table 1 Baseline demographic and clinical characteristics of patients

\begin{tabular}{|c|c|c|c|c|}
\hline & Global $(n=427)$ & Diabetics $(n=92)$ & Non-Diabetics $(n=335)$ & $p$ value \\
\hline Age (years) & $60.3 \pm 8.5$ & $59.7 \pm 84.5$ & $81.3 \pm 113.4$ & 0.483 \\
\hline Gender (women) n (\%) & $236(55.3)$ & $63(68.5)$ & $173(51.6)$ & 0.004 \\
\hline Smoker n (\%) & $82(21.5)$ & $19(20.7)$ & $73(21.8)$ & 0.887 \\
\hline Alcohol drinking (gr/week) & $76.6 \pm 108.1$ & $60.9 \pm 8.8$ & $60.2 \pm 8.4$ & 0.089 \\
\hline METs/hour/week & $3623 \pm 3431$ & $3378 \pm 3153$ & $3691 \pm 3506$ & 0.440 \\
\hline Body mass index $\left(\mathrm{kg} / \mathrm{m}^{2}\right)$ & $28.3 \pm 4.2$ & $29.8 \pm 5.0$ & $27.9 \pm 3.9$ & $<0.001$ \\
\hline Abdominal perimeter $(\mathrm{cm})$ & $97.5 \pm 10.6$ & $102.4 \pm 11.7$ & $96.2 \pm 9.9$ & $<0.001$ \\
\hline Obesity patients n (\%) & $128(27.6)$ & $38(41.3)$ & $80(23.9)$ & 0.001 \\
\hline Office SBP (mmHg) & $134 \pm 17$ & $137.0 \pm 14.7$ & $133.4 \pm 17.1$ & 0.067 \\
\hline Office DBP (mmHg) & $81 \pm 11$ & $79.7 \pm 10.1$ & $81.5 \pm 11.1$ & 0.169 \\
\hline Office MBP (mmHg) & $93 \pm 10$ & $93.4 \pm 9.2$ & $93.1 \pm 9.7$ & 0.783 \\
\hline Office Heart rate (bpm) & $70 \pm 11$ & $73.0 \pm 12.1$ & $69.3 \pm 10.8$ & 0.005 \\
\hline Hypertensive patients n (\%) & $340(79.6)$ & $76(82.6)$ & $264(78.8)$ & 0.468 \\
\hline Antihypertensive Drugs n (\%) & $230(53.9)$ & $60(65.2)$ & $170(50.7)$ & 0.018 \\
\hline $\mathrm{FPG}(\mathrm{mg} / \mathrm{dL})$ & $97.9 \pm 31.1$ & $137.5 \pm 46.1$ & $87.0 \pm 10.1$ & $<0.001$ \\
\hline Average PG (mg/dL) & $120.2 \pm 32.4$ & $152.4 \pm 9.5$ & $111.3 \pm 17.6$ & $<0.001$ \\
\hline HbA1c (\%) & $5.9 \pm 1.0$ & $7.2 \pm 1.4$ & $5.6 \pm 0.3$ & $<0.001$ \\
\hline Diabetics patients n (\%) & $92(21.5)$ & $92(21.5)$ & $0(0.0)$ & - \\
\hline Antidiabetic drugs n (\%) & $76(17.8)$ & $76(82.6)$ & $0(0.0)$ & - \\
\hline Total Cholesterol (mg/dl) & $215.0 \pm 38.93$ & $193.1 \pm 41.1$ & $221.0 \pm 36.1$ & $<0.001$ \\
\hline LDL Cholesterol (mg/dl) & $134.3 \pm 34.5$ & $113.4 \pm 35.5$ & $140.1 \pm 32.0$ & $<0.001$ \\
\hline HDL-Cholesterol (mg/dl) & $55.1 \pm 14.3$ & $51.6 \pm 13.0$ & $56.1 \pm 14.5$ & 0.009 \\
\hline Tryglicerides (mg/dl) & $129.4 \pm 92.6$ & $149.0 \pm 138.4$ & $124.0 \pm 74.8$ & 0.022 \\
\hline No HDL-Cholesterol (mg/dl) & $80.2 \pm 13.8$ & $79.8 \pm 16.3$ & $80.2 \pm 13.0$ & 0.805 \\
\hline Dyslipidemia patients n (\%) & $363(85)$ & $66(71.7)$ & $297(88.7)$ & $<0.001$ \\
\hline Lipid lowering drugs n (\%) & $158(37)$ & $56(60.9)$ & $102(30.4)$ & $<0.001$ \\
\hline Average mean IMT (mm) & $0.738 \pm 0.096$ & $0.768 \pm 0.111$ & $0.729 \pm 0.089$ & 0.001 \\
\hline Carotid plaques n (\%) & $75(17.6)$ & $28(30.4)$ & $47(14.1)$ & $<0.001$ \\
\hline TOD carotid n (\%) & $77(18.0)$ & $29(31.5)$ & $48(14.3)$ & $<0.001$ \\
\hline Average maxima IMT (mm) & $0.906 \pm 0.117$ & $0.942 \pm 0.136$ & $0.896 \pm 0.109$ & 0.001 \\
\hline
\end{tabular}

Values are means and standard deviations (SD) for distributed continuous data, and absolute frequencies and percentages (\%) for categorical data

METs metabolic equivalents, SBP systolic blood pressure, DBP diastolic blood pressure, MBP mean blood pressure, $F P G$ fasting plasma glucose, $P G$ postprandial glucose, HbA1c glycosylated hemoglobin, LDL low density lipoprotein, HDL high density lipoprotein, IMT intima-media thickness of common carotid artery, TOD target organ damage

No HDL-Cholesterol $\mathrm{mg} / \mathrm{dl}=$ (Total Cholesterol $-\mathrm{HDL}$ Cholesterol)

TOD = Plaque or carotid IMT $>0.90 \mathrm{~mm}$ 
drugs, antidiabetic drugs, alcohol drinking (gr/week) and METs/min/14 days (Model 2). To improve the final interpretation, the C-IMT was multiplied one hundred-fold. To estimate the odds ratio (OR), two models were constructed using the same adjust as the previous multiple linear regression analyses. The presence of carotid target organ damage (TOD) was considered to be a variable dependent and fasting glucose $(\mathrm{mg} / \mathrm{dL})$, average postprandial glycemia (mg/dL), HbA1c (\%) and altered glucose metabolism were considered to be independent variables. The data were analyzed using the Statistical Package for the Social Sciences version 20.0 (SPSS, Chicago, IL, USA). A value of $p<0.05$ was considered statistically significant.

\section{Results}

The characteristics of the study subjects, global diabetics and non-diabetics are shown in Table 1 . The mean age was $60.3 \pm 8.5$ years, and $55.3 \%$ of the subjects were women. The mean C-IMT was $0.738 \mathrm{~mm}(0.768 \pm 0.111$ in diabetics and $0.729 \pm 0.089$ in non diabetics).

Among the 335 non-diabetic subjects, 231 had normal glucose metabolism and 104 prediabetes, the percentage of subjects depending on the test used in the diagnosis shown in Fig. 1.

C-IMT shows a positive relationship with fasting glucose, average postprandial glycemia and HbA1c (Table 2). The 196 patients who have a glucose metabolic alteration also show mean C-IMT and C-IMT values of 0.039 and 0.044, which are higher than those in subjects without any glucose metabolic alteration (Additional file 1: Table S1).

Figure 2 and Additional file 1: Table S2 show the values of the C-IMT organized by tertiles of fasting glucose $(\mathrm{mg} / \mathrm{dL})$, average postprandial glycemia $(\mathrm{mg} / \mathrm{dL})$ and HbA1c.

A multiple linear regression analysis was performed (Table 3). In model 1, the C-IMT is associated with

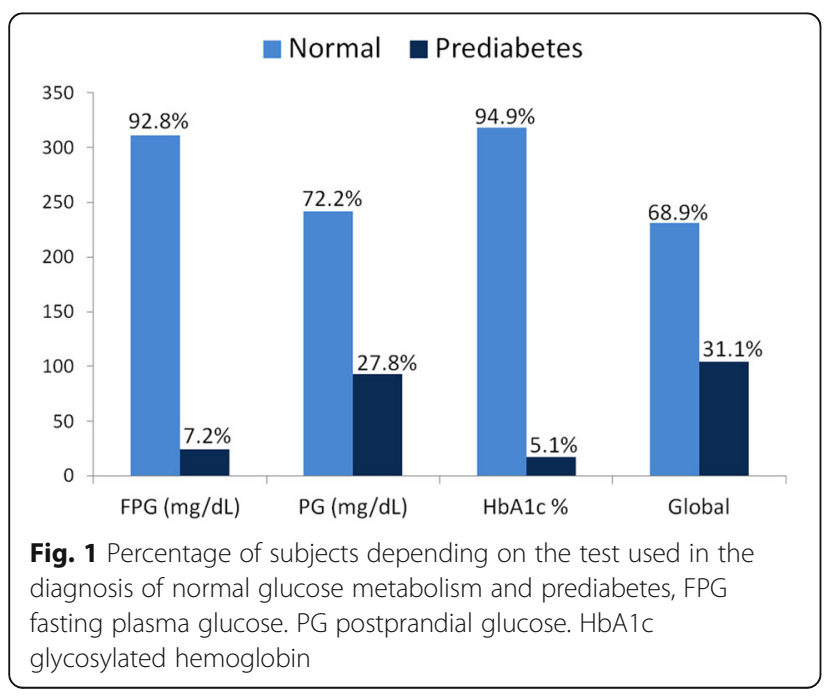

Table 2 Bivariate correlations of markers of dysglycemia with IMT and other cardiovascular risk factors

\begin{tabular}{lccc}
\hline & FPG $(\mathrm{mg} / \mathrm{dL})$ & $\begin{array}{c}\text { Average PG } \\
(\mathrm{mg} / \mathrm{dL})\end{array}$ & $\mathrm{HbA1c} \%$ \\
\hline Average mean IMT (mm) & $0.179^{* *}$ & $0.182^{* *}$ & $0.191^{* *}$ \\
Maxima men IMT (mm) & $0.173^{* *}$ & $0.207^{* *}$ & $0.182^{* *}$ \\
Age (year) & 0.058 & $0.157^{*}$ & 0.019 \\
Body mass index & $0.201^{* *}$ & 0.081 & $0.226^{* *}$ \\
Heart rate. bpm & $0.184^{* *}$ & $0.123^{*}$ & $0.155^{* *}$ \\
$\begin{array}{l}\text { No HDL-Cholesterol } \\
\text { (mg/dl) }\end{array}$ & $0.171^{* *}$ & 0.069 & 0.065 \\
$\begin{array}{l}\text { Systolic Blood Pressure } \\
\text { (mm Hg) }\end{array}$ & $0.115^{*}$ & 0.049 & 0.059 \\
Alcohol drinking (gr/week) & -0.064 & -0.075 & -0.094 \\
$\begin{array}{l}\text { METs/hour/week } \\
\text { M }\end{array}$ & $-0.130^{*}$ & -0.109 & -0.116 \\
\hline
\end{tabular}

IMT intima-media thickness of common carotid artery, FPG fasting plasma glucose, $P G$ postprandial glucose, $H b A 1 c$ glycosylated hemoglobin, $H D L$ high density lipoprotein, METs metabolic equivalents

$P$-values by Pearson correlation. ${ }^{*} p<0.05{ }^{* *} p<0.01$

different parameters that were used to measure glucose. After fully adjusting for all parameters (Model 2), CIMT maintains a positive association with fasting glucose and with HbA1c. For each $1 \%$ increase in HbA1c, the C-IMT mean increased $0.016 \mathrm{~mm}$ and the C-IMT maximum increased $0.019 \mathrm{~mm}$. For each $10-\mathrm{mg}$ increase in fasting plasma glucose, the C-IMT mean and maximum increase 0.004 and $0.005 \mathrm{~mm}$, respectively.

The association between IMT average mean and glucose in diabetic subjects and nondiabetic are set out in the Additional file 1: Table S3.

Table 4 shows the OR of the different markers of glycemia for the presence of carotid TOD. In Model 2, the association between fasting plasma glucose, postprandial glucose and HbA1c with the presence of carotid TOD is maintained $(\mathrm{OR}=1.013, \mathrm{OR}=1.010$ and $\mathrm{OR}=1.425$, respectively). Patients who have a glucose metabolic alteration have twice the risk of presenting with a carotid TOD $(\mathrm{OR}=1.920)$.

The 77 patients who presented with carotid TOD also presented with fasting glucose levels that were $15.10 \mathrm{mg} / \mathrm{ml}$ higher, average postprandial glycemia that was $18.69 \mathrm{mg} / \mathrm{ml}$ higher and HbA1c that was $0.47 \%$ higher than those without carotid TOD.

\section{Discussion}

The results of this study suggest that, in patients with an intermediate cardiovascular risk, there is a positive association between C-IMT and the basal glycemia and HbA1c levels, which is independent of age, drug treatment and other confounding factors. The probability of developing carotid TOD increases with different glycemia parameters. Similarly, patients who present with a glucose metabolic alteration have twice the risk of developing TOD. 

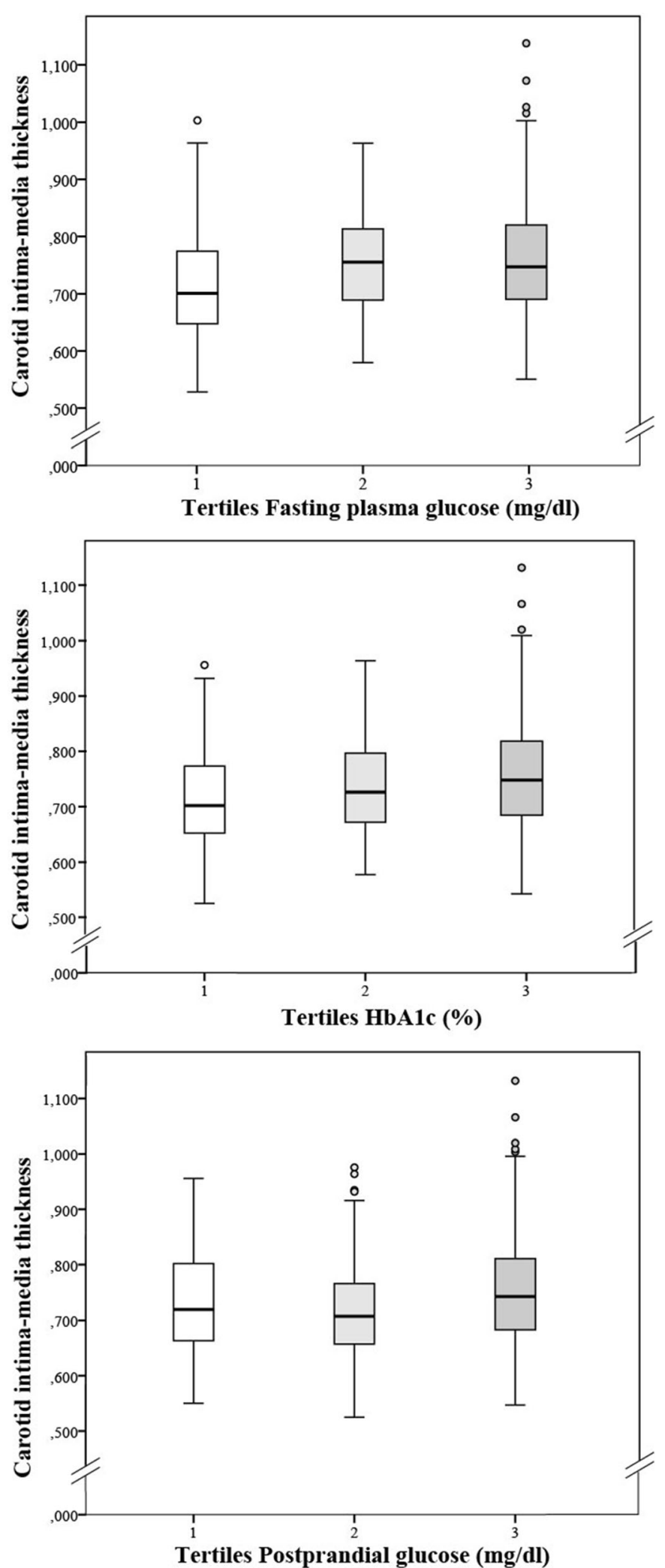

Fig. 2 ANOVA test results: Carotid intima media thickness by tertiles of fasting plasma glucose $(\mathrm{mg} / \mathrm{dl})$, postprandial glucose (mg/dl) and glycated hemoglobin (\%) 
Table 3 Multiple regression analysis with vascular structure as dependent variable and markers of dysglycemia as independent variable

\begin{tabular}{llll}
\hline Dependent variable: & $\beta$ & Cl $95 \%$ & $p$ value \\
\hline Average mean IMT Model 1 & & & \\
FPG (mg/dL) & 0.046 & 0.020 to 0.073 & 0.001 \\
Average PG (mg/dL) & 0.035 & 0.009 to 0.060 & 0.008 \\
HbA1c (\%) & 1.658 & 0.813 to 2.503 & $<0.001$ \\
Average maxima IMT Model 1 & & & \\
FPG (mg/dL) & 0.055 & 0.022 to 0.088 & 0.001 \\
Average PG (mg/dL) & 0.041 & 0.009 to 0.072 & 0.012 \\
HbA1c \% & 1.955 & 0.908 to 0.302 & $<0.001$ \\
Average mean IMT Model 2 & & & \\
FPG (mg/dL) & 0.042 & 0.002 to 0.082 & 0.040 \\
Average PG (mg/dL) & 0.021 & -0.010 to 0.051 & 0.188 \\
HbA1c (\%) & 1.589 & 0.435 to 2.771 & 0.009 \\
Average maxima IMT Model 2 & & \\
FPG (mg/dL) & 0.052 & 0.002 to 0.102 & 0.042 \\
Average PG (mg/dL) & 0.024 & -0.015 to 0.062 & 0.225 \\
HbA1c (\%) & 1.907 & 0.435 to 3.378 & 0.011
\end{tabular}

Dependent variable: IMT: Intima-media thickness of common carotid artery Indepedent variable: fasting glucose $(\mathrm{mg} / \mathrm{dL})$, average postprandial glycemia $(\mathrm{mg} / \mathrm{dL})$ and $\mathrm{HbA} 1 \mathrm{c}(\%)$

Adjusted by: Model 1: age and gender

Modelo 2: age, gender, heart rate, smoker, body mass index, no HDL-Cholesterol, systolic blood pressure, diabetes mellitus, antihypertensive drugs, lipid lowering drugs, antidiabetic drugs alcohol drinking (gr/week), METs/hour/week

$\beta$ regression coefficient, $\mathrm{Cl}$ confidence interval, IMT intima-media thickness of common carotid artery, FPG fasting plasma glucose, $P G$ postprandial glucose, HbA1C glycosylated hemoglobin

In this study, for each percentage point increase in HbA1c, the mean C-IMT increases by $0.016 \mathrm{~mm}$ and the maximum C-IMT increases by 0.019 . Our results are consistent with previous studies that were performed in the Chinese general population [26], and also consistent with results from the non-diabetic population of a multi-ethnic atherosclerosis study [11] However, Haring et al. [27] found a positive association between HbA1c and mean C-IMT, with a $0.02 \mathrm{~mm}$ increase in C-IMT per $1 \%$ increase in $\mathrm{HbA} 1$, but this association did not remain in the longitudinal analysis.

The association with $2 \mathrm{~h}$ postprandial glycemia was lost after adjusting for confounding factors, and the logistic regression maintained an OR of 0.010. Previous publications had different conclusions. For example, $1 \mathrm{~h}$ after glucose overload glycemia was found to be the only factor associated with C-IMT after adjusting for different cardiovascular risk factors in a linear regression analysis [14]. This association was not present $2 \mathrm{~h}$ after glucose overload, but the latter association was found by others authors $[6,13]$. Similarly, in type 2 diabetes patients, the maximum increase in glycemia is registered within the first hour after a meal, and this showed a stronger
Table 4 Logistic regression analysis with vascular structure as dependent variable and markers of dysglycemia as independent variable

\begin{tabular}{lccc}
\hline Dependent variable: & OR & Cl 95 \% & $p$ value \\
\hline With and without TOD of cartic Modelo 1 & & \\
FPG (mg/dL) & 1.012 & 1.005 to 1.020 & 0.001 \\
Average PG (mg/dL) & 1.012 & 1.005 to 1.020 & 0.001 \\
HbA1c (\%) & 1.492 & 1.189 to 1.872 & 0.001 \\
Altered glucose metabolism & 2.153 & 1.217 to 3.629 & 0.004 \\
With and without TOD of carotic Modelo 2 & & \\
FPG (mg/dL) & 1.013 & 1.001 to 1.025 & 0.039 \\
Average PG (mg/dL) & 1.010 & 1.001 to 1.019 & 0.010 \\
HbA1c (\%) & 1.425 & 1.026 to 1.980 & 0.034 \\
Altered glucose metabolism* & 1.920 & 1.079 to 3.415 & 0.026 \\
\hline
\end{tabular}

Dependent variable: target organ damage of carotid

Indepedent variable: fasting glucose $(\mathrm{mg} / \mathrm{dL})$, average postprandial glycemia $(\mathrm{mg} / \mathrm{dL})$ and $\mathrm{HbA1c}(\%)$

Adjusted by: Model 1: age and gender

Modelo 2: age, gender, heart rate, smoker, body mass index, no HDL-Cholesterol, systolic blood pressure, diabetes mellitus, antihypertensive drugs, lipid lowering drugs, antidiabetic drugs alcohol drinking (gr/week), METs/hour/week

$O R$ odds ratio, $\mathrm{Cl}$ confidence interval, TOD target organ damage, FPG fasting plasma glucose, $P G$ postprandial glucose, $H b A 1 c$ glycosylated hemoglobin TOD $=$ Plaque or carotid IMT $>0.90 \mathrm{~mm}(n=77)$

*Altered glucose metabolism including diabetes and prediabetes subjects $(n=196)$

correlation with C-IMT than with other glycemia markers such as HbA1C, fasting glucose and glucose $2 \mathrm{~h}$ after a meal [28].

A glucose metabolic alteration doubles the risk of developing carotid TOD. These results are similar to those of Kurihara et al. [29], who concluded that arteriosclerotic disease in the coronary artery and the vulnerability to plaque are more progressed in pre-diabetics and diabetics than in non-diabetics. However, the relationship in pre-diabetic patients is statistically significant after adjustment for other cardiovascular risk factors [6].

Other studies that also analyzed the association between different measurements of glycemia using C-IMT $[1,13,30,31]$ and found divergent results. In our study, the independent association of the $\mathrm{HbA1C}$ and fasting glucose with the mean and maximum C-IMT remains after the adjustment for age, sex, drug treatment and others cofounding cardiovascular factors, including the association between the above-mentioned parameters and glucose levels $2 \mathrm{~h}$ after a meal. These differences could be explained by the heterogeneity of the studies, different protocols used to measure C-IMT, different parameters used to assess glycemia, different ethnicities included in the studies (for example, Caucasian vs. Asian) and other features of the subjects such as body mass index or the prevalence of different cardiovascular risk factors and different variables used to adjust for confounding factors.

These studies suggest that more prospective studies that analyze the relationship between glycemia and the 
C-IMT are needed, and that they should include different ethnicities. Studies that analyze how glycemia at 1 and $2 \mathrm{~h}$ after a meal or glucose overload develops, and its association with C-IMT are required to establish which postprandial glycemia value is better associated with subclinical atherosclerotic disease.

\section{Limitations}

This study has several limitations that should be considered in the interpretation of our results. First, because the study sample comprised exclusively Caucasian adults with an intermediate cardiovascular, our results may not be generalizable to other ethnic groups. The observational study design and the cross-sectional nature of the positive association between markers of glycemia and C-IMT as an intermediate risk marker for subclinical atherosclerosis does not prove causality. Finally, glucose intolerance was not performed with oral glucose tolerance test with $75 \mathrm{~g}$ of glucose. It was determined with the mean capillary blood glucose $2 \mathrm{~h}$ after breakfast, lunch and dinner. However, this is the first study to examine the relationship between the markers of glycemia and vascular structure, as assessed using the C-IMT, in intermediate-risk cardiovascular patients.

\section{Conclusion}

In conclusion, the results of this study suggest that the fasting plasma glucose and the HbA1c levels, but not postprandial glucose, are associated with the mean and maximum C-IMT. Patients who present the glucose metabolic alteration have more risk of developing carotid TOD compared with patients with no glucose metabolic alterations.

\section{Additional file}

Additional file 1: Table S1. Parameters of vascular structure by tertiles of markers of glycemia. (DOCX $17 \mathrm{~kb}$ )

\section{Abbreviations \\ ABI: Ankle-brachial index; BMI: Body mass index; BP: Blood pressure; CAVI: Cardio-ankle vascular index; C-IMT: Carotid intima-media thickness; CSBP: Central systolic blood pressure; DBP: Diastolic blood pressure; HbA1c: Hemoglobin A1c; HDL: High-density lipoprotein; IQR: Interquartile range; LTPA: Leisure time physical activity; METs: Metabolic equivalents; PAD: Peripheral arterial disease; SBP: Systolic blood pressure; TOD: Target organ damage}

\section{Acknowledgments}

We are grateful to all professionals participating in the MARK study. Lead author for this group: Rafel Ramos, Research Unit, Primary Health Care, Girona, Jordi Gol Institute for Primary Care Research (IDIAP Jordi Gol), Catalonia, Spain, E-mail: rramos.girona.ics@gencat.net. Coordinating Center: Rafel Ramos, Ruth Martí, Dídac Parramon, Anna Ponjoan, Miquel Quesada, Maria Garcia-Gil, Martina Sidera and Lourdes Camós, Research Unit, Primary Health Care, Jordi Gol Institute for Primary Care Research (IDIAP Jordi Gol), C/Maluquer Salvador, 11, 17002-Girona, Catalonia, Spain. Fernando Montesinos, Ignacio Montoya, Carlos López, Anna Agell, Núria Pagès of the Primary Care Services, Girona, Catalan Institute of Health (ICS), Catalonia, Spain. Irina Gil, Anna Maria-Castro of the Primary Care Services, Girona, Institut d'Assistència Sanitaria
(IAS), Catalonia, Spain. Fernando Rigo, Guillermo Frontera, Antònia Rotger, Natalia Feuerbach, Susana Pons, Natividad Garcia, John Guillaumet, Micaela Llull and Mercedes Gutierrez of the Health Center Primary Care San Augustín, Ibsalut Balears, Spain. Cristina Agudo-Conde, Leticia Gómez-Sanchez, Carmen Castaño-Sanchez, Carmela Rodriguez-Martín, Benigna Sanchez-Salgado, Angela de Cabo-Laso, Emiliano Rodriquez-Sanchez, Jose Angel Maderuelo-Fernandez, Emilio Ramos-Delgado, Carmen Patino-Alonso, Jose I Recio-Rodriguez, Manuel A Gomez-Marcos and Luis Garcia-Ortiz, Primary Care Research Unit of The Alamedilla, Salamanca, Spain, Castilla and León Health Service-SACYL.

\section{Funding}

This work was supported by grants from the Spanish Ministry of Science and Innovation (MICINN), the Carlos III Health Institute/European Regional Development Fund (ERDF) (MICINN, ISCIII/FEDER) (Red RedIAPP RD12/0005, Research Groups: RD12/0005/0004, RD12/0005/0002, RD12/0005/0011), the Health Research Fund (PI10/01088, PI10/02077, PI10/02043), and the Regional Health Management of the Castilla and León (GRS 635/A/11; GRS 906/B/14).

\section{Availability of data and materials}

All relevant data supporting the conclusions of this article is included within the article.

\section{Authors' contributions}

LGS prepared the manuscript draft, participated in fund raising and interpretation of results, and corrected the final version of the manuscript. JIR participated in the study design, interpretation of results, and manuscript review. CA and FR participated in data collection and manuscript review. MCP and VM performed all analytical methods, interpretation of results and manuscript review. RR, RR, LG and MAG participated in the protocol design, fund raising, analysis of results and final review of the manuscript. All authors reviewed and approved the final version of the manuscript.

\section{Competing interests}

The authors declare that they have no competing interests.

\section{Consent for publication}

Not applicable.

\section{Ethics approval and consent to participate}

The study was approved by an independent ethics committee from the Salamanca health area (Spain), and all participants gave written informed consent according to the general recommendations of the Helsinki Declaration.

\section{Author details}

'Primary Care Research Unit, the Alamedilla Health Center, 37003 Salamanca, Spain. ${ }^{2}$ Castilla and León Health Service-SACYL, REDIAPP. IBSAL, Salamanca, Spain. ${ }^{3}$ Medicine Department, University of Salamanca, Salamanca, Spain. ${ }^{4}$ Statistics Department, University of Salamanca, Salamanca, Spain. ${ }^{5} \mathrm{CS}$ San Agustín, Primare Care Ibsalut, Palma of Mallorca, Spain. ${ }^{6}$ Research Unit, Family Medicine, Girona, Spain. ${ }^{7}$ Jordi Gol Institute for Primary Care, Research (IDIAP Jordi Gol), Girona, Spain. ${ }^{8}$ Translab Research Group. Department of Medical Sciences, School of Medicine, University of Girona, Girona, Spain. ${ }^{9}$ Girona Biomedical Research Institute (IDIBGI), Dr. Trueta University Hospital, Catalonia, Spain. ${ }^{10}$ MARK Group. redIAPP: Research Network on Preventive Activities and Health Promotion, Girona, Spain.

Received: 7 May 2016 Accepted: 22 October 2016

Published online: 28 October 2016

References

1. Sarwar N, Gao P, Seshasai SR, Gobin R, Kaptoge S, Di Angelantonio E, Ingelsson E, Lawlor DA, Selvin E, Stampfer M, et al. Diabetes mellitus, fasting blood glucose concentration, and risk of vascular disease: a collaborative meta-analysis of 102 prospective studies. Lancet. 2010;375(9733):2215-22.

2. Selvin E, Marinopoulos S, Berkenblit G, Rami T, Brancati FL, Powe NR, Golden SH. Meta-analysis: glycosylated hemoglobin and cardiovascular disease in diabetes mellitus. Ann Intern Med. 2004;141(6):421-31.

3. Faeh D, William J, Yerly P, Paccaud F, Bovet P. Diabetes and pre-diabetes are associated with cardiovascular risk factors and carotid/femoral intima-media 
thickness independently of markers of insulin resistance and adiposity. Cardiovasc Diabetol. 2007;6:32.

4. Gomez-Marcos MA, Recio-Rodriguez Il, Patino-Alonso MC, Agudo-Conde C, Gomez-Sanchez L, Rodriguez-Sanchez E, Gomez-Sanchez M, Garcia-Ortiz L. Yearly evolution of organ damage markers in diabetes or metabolic syndrome: data from the LOD-DIABETES study. Cardiovasc Diabetol. 2011;10:90.

5. Tripolt NJ, Narath SH, Eder M, Pieber TR, Wascher TC, Sourij H. Multiple risk factor intervention reduces carotid atherosclerosis in patients with type 2 diabetes. Cardiovasc Diabetol. 2014;13:95.

6. Xing FY, Neeland IJ, Gore MO, Ayers CR, Paixao AR, Turer AT, Berry JD, Khera A, de Lemos JA, McGuire DK. Association of prediabetes by fasting glucose and/or haemoglobin A1c levels with subclinical atherosclerosis and impaired renal function: observations from the Dallas Heart Study. Diab Vasc Dis Res. 2014;11(1):11-8.

7. Brohall G, Oden A, Fagerberg B. Carotid artery intima-media thickness in patients with Type 2 diabetes mellitus and impaired glucose tolerance: a systematic review. Diabet Med. 2006;23(6):609-16.

8. Andreozzi F, Gastaldelli A, Mannino GC, Sciacqua A, Succurro E, Arturi F, Folli $F$, Perticone F. Increased carotid intima-media thickness in the physiologic range is associated with impaired postprandial glucose metabolism, insulin resistance and beta cell dysfunction. Atherosclerosis. 2013;229(2):277-81.

9. Choi SW, Shin MH, Yun WJ, Kim HY, Lee YH, Kweon SS, Rhee JA, Choi JS. Association between hemoglobin A1c, carotid atherosclerosis, arterial stiffness, and peripheral arterial disease in Korean type 2 diabetic patients. J Diabetes Complications. 2011;25(1):7-13.

10. Saba L, Ikeda N, Deidda M, Araki T, Molinari F, Meiburger KM, Acharya UR, Nagashima Y, Mercuro G, Nakano M, et al. Association of automated carotid IMT measurement and $\mathrm{HbA1C}$ in Japanese patients with coronary artery disease. Diabetes Res Clin Pract. 2013;100(3):348-53.

11. McNeely MJ, McClelland RL, Bild DE, Jacobs Jr DR, Tracy RP, Cushman M, Goff Jr DC, Astor BC, Shea S, Siscovick DS. The association between A1C and subclinical cardiovascular disease: the multi-ethnic study of atherosclerosis. Diabetes Care. 2009;32(9):1727-33.

12. Huang Y, Bi Y, Wang W, Xu M, Xu Y, Li M, Wang T, Chen Y, Li X, Ning G. Glycated hemoglobin A1c, fasting plasma glucose, and two-hour postchallenge plasma glucose levels in relation to carotid intima-media thickness in chinese with normal glucose tolerance. J Clin Endocrinol Metab. 2011;96(9):E1461-5.

13. Kato K, Otsuka T, Kobayashi N, Kon Y, Kawada T. Two-hour post-load plasma glucose levels are associated with carotid intima-media thickness in subjects with normal glucose tolerance. Diabet Med. 2014;31(1):76-83.

14. Tanaka K, Kanazawa I, Yamaguchi T, Sugimoto T. One-hour post-load hyperglycemia by $75 \mathrm{~g}$ oral glucose tolerance test as a novel risk factor of atherosclerosis. Endocr J. 2014;61(4):329-34.

15. Ho HC, Chen MF, Hwang JJ, Lee YT, Su TC. Intima-media thickness of lowerlimb arteries associated with fasting and post-challenge plasma glucose levels. J Atheroscler Thromb. 2009;16(6):748-55.

16. Marti R, Parramon D, Garcia-Ortiz L, Rigo F, Gomez-Marcos MA, Sempere I, Garcia-Regalado N, Recio-Rodriguez Jl, Agudo-Conde C, Feuerbach N, et al. Improving interMediAte risk management. MARK study. BMC Cardiovasc Disord. 2011;1:61

17. Marrugat J, D'Agostino R, Sullivan L, Elosua R, Wilson P, Ordovas J, Solanas P, Cordon F, Ramos R, Sala J, et al. An adaptation of the Framingham coronary heart disease risk function to European Mediterranean areas. J Epidemiol Community Health. 2003;57(8):634-8.

18. Conroy RM, Pyorala K, Fitzgerald AP, Sans S, Menotti A, De Backer G, De Bacquer D, Ducimetiere P, Jousilahti P, Keil U, et al. Estimation of ten-year risk of fatal cardiovascular disease in Europe: the SCORE project. Eur Heart J. 2003;24(11):987-1003.

19. Mancia G, Fagard R, Narkiewicz K, Redon J, Zanchetti A, Bohm M, Christiaens T, Cifkova R, De Backer G, Dominiczak A, et al. 2013 ESH/ESC Guidelines for the management of arterial hypertension: the Task Force for the management of arterial hypertension of the European Society of Hypertension (ESH) and of the European Society of Cardiology (ESC). J Hypertens. 2013;31(7):1281-357.

20. Standards of Medical Care in Diabetes-2016: Summary of Revisions. Diabetes Care 2016, 39 Suppl 1:S4-5.

21. World Medical Association. World Medical Association Declaration of Helsinki: ethical principles for medical research involving human subjects. JAMA. 2013;310(20):2191-4.

22. O'Brien $E$, Asmar R, Beilin L, Imai Y, Mancia G, Mengden T, Myers M, Padfield P, Palatini P, Parati G, et al. Practice guidelines of the European Society of
Hypertension for clinic, ambulatory and self blood pressure measurement. J Hypertens. 2005;23(4):697-701.

23. Gomez-Marcos MA, Recio-Rodriguez II, Patino-Alonso MC, Agudo-Conde C, Gomez-Sanchez L, Gomez-Sanchez M, Rodriguez-Sanchez E, Garcia-Ortiz L. Protocol for measuring carotid intima-media thickness that best correlates with cardiovascular risk and target organ damage. Am J Hypertens. 2012; 25(9):955-61.

24. Elosua R, Marrugat J, Molina L, Pons S, Pujol E. Validation of the Minnesota Leisure Time Physical Activity Questionnaire in Spanish men. The MARATHOM Investigators. Am J Epidemiol. 1994;139(12):1197-209.

25. Elosua R, Garcia M, Aguilar A, Molina L, Covas MI, Marrugat J. Validation of the Minnesota Leisure Time Physical Activity Questionnaire In Spanish Women. Investigators of the MARATDON Group. Med Sci Sports Exerc. 2000;32(8):1431-7.

26. Hung CS, Lee PC, Li HY, Ma WY, Lin MS, Wei JN, Shih SR, Hua CH, Chuang LM, Chen MF. Haemoglobin A1C is associated with carotid intima-media thickness in a Chinese population. Clin Endocrinol (Oxf). 2011;75(6):780-5.

27. Haring R, Baumeister SE, Lieb W, von Sarnowski B, Volzke H, Felix SB, Nauck $\mathrm{M}$, Wallaschofski $\mathrm{H}$. Glycated hemoglobin as a marker of subclinical atherosclerosis and cardiac remodeling among non-diabetic adults from the general population. Diabetes Res Clin Pract. 2014;105(3):416-23.

28. Esposito K, Ciotola M, Carleo D, Schisano B, Sardelli L, Di Tommaso D, Misso L, Saccomanno F, Ceriello A, Giugliano D. Post-meal glucose peaks at home associate with carotid intima-media thickness in type 2 diabetes. J Clin Endocrinol Metab. 2008;93(4):1345-50.

29. Kurihara O, Takano M, Yamamoto M, Shirakabe A, Kimata N, Inami T, Kobayashi N, Munakata R, Murakami D, Inami S, et al. Impact of prediabetic status on coronary atherosclerosis: a multivessel angioscopic study. Diabetes Care. 2013;36(3):729-33.

30. Kim HK, Lee JB, Kim SH, Jo MW, Kim EH, Hwang JY, Bae SJ, Jung CH, Lee WJ, Park JY, et al. Association of prediabetes defined by fasting glucose, $\mathrm{HbA1c}$ only, or combined criteria with the risk of cardiovascular disease in Koreans. J Diabetes. 2015;8:657-66.

31. Succurro E, Marini MA, Arturi F, Grembiale A, Lugara M, Andreozzi F, Sciacqua A, Lauro R, Hribal ML, Perticone F, et al. Elevated one-hour postload plasma glucose levels identifies subjects with normal glucose tolerance but early carotid atherosclerosis. Atherosclerosis. 2009;207(1):245-9.

\section{Submit your next manuscript to BioMed Central and we will help you at every step:}

- We accept pre-submission inquiries

- Our selector tool helps you to find the most relevant journal

- We provide round the clock customer support

- Convenient online submission

- Thorough peer review

- Inclusion in PubMed and all major indexing services

- Maximum visibility for your research

Submit your manuscript at www.biomedcentral.com/submit
) Biomed Central 